\title{
Imbuing Education with Brain Research Can Improve Teaching and Enhance Productive Learning
}

\author{
Isaac A. Friedman, Etty Grobgeld, Ariela Teichman-Weinberg \\ The Achva Academic College, Be'er Tuvia Regional Council, Israel \\ Email: isaac685@gmail.com
}

How to cite this paper: Friedman, I. A., Grobgeld, E., \& Teichman-Weinberg, A. (2019). Imbuing Education with Brain Research Can Improve Teaching and Enhance Productive Learning. Psychology, 10, 122-131.

https://doi.org/10.4236/psych.2019.102010

Received: November 20, 2018

Accepted: January 29, 2019

Published: February 1, 2019

Copyright (c) 2019 by author(s) and Scientific Research Publishing Inc. This work is licensed under the Creative Commons Attribution International License (CC BY 4.0). http://creativecommons.org/licenses/by/4.0/

\begin{abstract}
The article presents an experimental three-year Neuropedagogy Adaptation Project (NAP) that exposed practicing teachers to neuroscientific concepts and research findings in order to merge them with their teaching and classroom management practice. The project addressed two basic issues. First, selecting pertinent neuroscientific content areas that are best applicable to teaching and learning. Second, establishing a methodology and practice to infuse education with neuroscientific knowhow. The article gives an account of the project's guidelines, and participants' applications of neuroscientific concepts to classroom practices, and teacher student relationships. Based on the conclusions derived from the project, we argue that the time is ripe for establishing a new educational discipline-Neuropedagogy that is a blend of neuroscience, neurocognitive psychology and education.
\end{abstract}

\section{Keywords}

Neuropedagogy, Improving Teaching and Learning, Innovations in Teaching,

Teaching Practices, Teacher-Students Relations, Teacher Education,

Teachers' Professional Development, School Principals Professional

Development

\section{Introduction}

The search for ways to improve teaching and enhance learning is an issue of prevailing interest for most if not all educational systems in the Western world. In recent years, there has been an influx of voices seeking to implement neuroscience knowledge and research findings into the realm of pedagogy and classroom teaching for advancing teaching and learning (Ansari, Koning, Leask, \& 
Tokuhama-Espinosa, 2017; Ansari, Smedt, \& Grabner, 2011; Fischer \& Daniel, 2009; Tokuhama-Espinosa, 2018). For example, Friedman, Teichman-Weinberg, \& Grobgeld (2016) argued that insights about the mode in which the brain functions and develops, and breakthroughs regarding the neural processes involved in acquiring, analyzing, and storing information can potentially change the process of teaching and ameliorate learning. Tokuhama-Espinosa $(2011,2016)$ reported, following a comprehensive review of current endeavors for infusing the knowhow of neurocognitive processes with learning, that the knowledge derived from neuroscientific research might offer new perspectives on teaching and learning. Dubinsky, Roehrig, \& Varma (2013) provided evidence indicating that it might be beneficial to inform teachers of neuroscience research findings and their implications for teaching. In addition, Levit-Binnun, Hadar, Albelda, and Ergaz (2018) pointed to a growing sense among educators that neuroscience can serve as an important turning point in initiating evidence-based pedagogical and educational practices, which in turn will serve to empower teachers' professional performance.

Hence, it seems consensual to a reasonable degree to hold that brain research can help teachers to enhance their educational and teaching capabilities. However, three main questions remain open: first, what are the neuroscience content areas or neuroscientific findings that are most pertinent to teaching and learning? Second, how to provide teachers with the relevant neuroscience concepts and knowhow in an intelligible and applicable way to initiate new, improved teaching practices and interactions with students? Third, how can neuroscience knowhow be translated into the educational practice in practical terms? These are no simple questions, especially given that experts in the biological or the neuroscience disciplines rarely provide overt information that is accessible to and usable by teachers and educators in general, and that transforming scientific knowledge into daily practice, especially in a different professional domain, is rarely immediate (Daniel, 2014).

With an intention of tackling the open questions stated above, we initiated a three-year Neuropedagogy Adaptation Project (NAP) to expose practicing teachers to neuroscientific knowledge in a comprehensible fashion for productive classroom practices. In this article, we shall give an account of the project outlines and contents, as well as the participants' testimonies regarding their experiences in applying neuroscientific findings to the realm of teaching, classroom management, and their daily routine as neuro-pedagogical practicing teachers.

\section{Purposes}

The Neuropedagogy Adaptation Project (NAP) intended to examine ways to apply neuroscience concepts and research findings to the realm of education, and to initiate guidelines for a new scientific discipline- "Neuropedagogy". In practical terms, the project aimed for attaining three main goals: 1) to select the most pertinent neuroscience concepts and knowhow that is applicable to teaching and 
learning, 2) to apply neuroscientific knowhow to classroom practice in a comprehensible fashion, and 3) unfold the usefulness and benefits gained from applying neuroscience concepts to education. The NAP was not destined to assess the effects of exposure to neuroscience research findings on improved kindergarteners or schoolchildren academic achievements. To conduct such a study would have required a completely different approach and methodology.

\section{Participants and Procedure}

Some 80 in-service k-12 teachers and educational staff at various kindergartens and schools in Israel participated in the three-year Neuropedagogy Adaptation Project (NAP) during the academic years 2016 through 2018. Most of the students, if not all, did not have prior knowledge in biology or neuroscience; this was their first exposure to the brain and its functions. The attempt to link knowledge regarding the structure and function of the brain with educational processes was unprecedented for them. A semester-long (and from 2017 on a 2 semester) class of a Master's degree program at a teacher training college constituted the program. Participation in the project was on a voluntary basis, as part of the elective courses offered in the Master's degree program. The course title was "Neuropedagogy: Brain Research for Improving Teaching and Learning". Three instructors from the fields of cognitive neuropsychology and education, neurobiology, as well as biochemistry, conducted the course.

Based on the guidelines published by the Society for Neuroscience in the US ${ }^{1}$, the following topics comprised the learning: 1) The Central nervous system-general structure and the plasticity of the brain. 2) Memory and learning-how the brain learns, remembers, and forgets. 3) Executive functions; 4) Attention, emotions and related disorders. 5). Dopamine and serotonin cycles in the brain. 6) Sleep and wakefulness cycle; and 7) Mindfulness and its relation to improving learning achievements.

The project participants were encouraged to devise, on their own initiative, innovative educational approaches by applying neuroscience knowledge to classroom teaching practice. In addition, they were required to note the considerations that guided them in selecting the particular parts of the expertise they have acquired, and the ways in which they integrated the knowledge into their daily work. All project participants provided written reports of their experiences. They presented their reports to the class, which were the subject of peer deliberations and discussions. Students' written reports were later content analyzed according to acceptable standards (Krippendorff, 2004).

\section{Results}

The project participants pointed to 10 topics as particularly relevant and important for their teaching practices. They are: 1). General insights regarding memo-

${ }^{1}$ Society for Neuroscience (2008). Neuroscience Core Concepts-the essential principals of neuroscience. 
ry, and the ways to improve learning. 2) Working memory ${ }^{2}$ and its role in learning. 3) Memory storage and retrieving stored information. 4) Attention and memory. 5) Prior knowledge as a basis for acquiring new information and learning. 6) Repetition of newly introduced information as a method for internalizing, and priming ${ }^{3}$. 7) Increasing the efficacy of teaching by extending class teaching over a wider time span. 8) Emotions and their relation to learning, memory and social behavior. 9) Motivation and learning. 10) The Daily cycle of wakefulness and sleep (the Circadian Circle).

Content analysis of the project participants' reports revealed the following four major themes: 1) Applying basic neuroscientific knowhow to education is essential for contemporary teaching practices. 2) Neuroscience provides confirmation of teachers' commonly used pedagogical practices, and enhances teachers' confidence in their professional capacity. 3) Knowing how the brain works allows for constructing different teaching methods, and therefore neuroscience know-how can provide options for devising new learning practices. 4) Acquiring understanding of how young people's brain functions guides teachers in changing their approach to their students. We shall elaborate on the themes in the following sections.

1) Applying basic neuroscientific knowhow to education is essential for contemporary teaching practices. In their reports, all the project participants highlighted the significance of the Neuropedagogy Adaptation Project (NAP) contents to their teaching, in addition to noting the novelty and richness of the information acquired. The following three excerpts can serve as characteristic examples.

a) As teachers, in order to understand and facilitate teaching and learning, nowadays we are called upon to delve deeper and deeper into other fields, such as the processes that take place in the human brain while learning. This understanding is a key factor for improving the efficacy of teaching and learning... This significant information allows us to rely not only on our intuition as educators, but also on a scientific foundation, grounded in research pertaining to the processes of learning and memory. Exposure to scientific information allows for a greater understanding and for linking this information to pedagogical and educational approaches and methods. The course enabled us as educators to understand basic concepts, to acquire new understanding [of the learning process. The course provided us with enormous amount of much-needed information and knowledge that has various implications for our work, which teachers can implement according to their own individual and personal experience. (Nearly all of the students verbalized this idea in several different ways).

b) Teachers often are given reports from various types of diagnosticians and therapists, with specific recommendations regarding the ways of coping with

${ }^{2}$ Working memory is short-term memory intended for carrying out a task in the immediate future based on the content of the memory.

${ }^{3}$ Priming is a concept that refers to analyzing perceptual information based on the prior encounter with this information, or similar information, regardless of whether the prior encounter was conscious or unconscious. 
difficulties and deficits. However, these recommendations and guidelines are not always clear to the members of the education staff, who have no previous training in special education or special needs. Hence, information from the field of neuroscience can address this lacuna and enable the teacher to comprehend the report and the recommendations provided by the specialist (Reported by two students).

c) The neuroscientific finding that most impressed me was that intelligence is not predetermined at birth; rather, the development of the brain and intelligence in early childhood is a malleable process. The influence of the environment compared to the influence of genetics makes us, as teachers, a very important factor in developing students' thinking abilities; essentially, they are like putty in our hands. It is very important for teachers and educators to understand the immense influence of the learning environment, and its capacity to improve the learning and teaching process (Reported by one student).

2) Neuroscience provides confirmation of teachers' commonly used pedagogical practices, and enhances teachers' confidence in their professional capacity.

The introduction to the learning mechanisms of the brain provided evidence in support of the pedagogical methods that have long been in use by teachers. The majority of the Neuropedagogy Adaptation Project participants reported on gaining confirmation for the validity of commonly used teaching approaches and methods. As one participant has put it: "We always did so, but now we have the grounds to believe that we are doing the right thing." Another student stated the following:

Throughout the course, I acquired "confirmation" and "scientific proof." that the teaching practices and methods that I use on a daily basis, which were established over a prolonged period of time-some go back to my initial training as a teacher, others are based on the experience I accumulated, and some on personal intuition. All of these are indeed effective and well suited to the human brain structure and the processes that take place within it... (An idea repeated in various forms by all of the students.)

One of the project participants, an English teacher who teaches language through music, related to several parts of the NAP content that provided an explanation for the successful outcomes of her teaching approach: "The musicaltune of a song can facilitate, to some extent, the process of learning and memory. The contents of song lyrics are better preserved in memory when introduced by means of a tune, than when introduced as statements."

Another project participant formulated an explanation for the link between enjoyment of music and the motivation to learn:

Music is enjoyable. Students listen to a song [in class] and then continue singing it outside the classroom. If I selected a song with lyrics that I wished students to remember, and they listened to the song repeatedly, this constitutes learning. The pleasure of hearing music causes the brain to secrete dopamine, which creates a sense of pleasure and increases motivation. Thus, the dopamine 
allows for persistent repetition without boredom...

In addition to increasing participants' professional confidence in their teaching methods, it appears that the project increased their confidence in facing students' parents. "What we learned helped me professionally, as it provided scientific clarity for my' gut feeling' and helped me initiate the discourse with parents on a different, more professional level' (the majority of the students pointed to this idea in their reports).

3) Knowing how the brain works allows for the construction of different teaching methods. Thus, neuroscience knowhow can initiate directions for devising new learning practices.

The NAP participants indicated that they were able to conceive of new ways of thinking and acting as teachers, as one of the participants stated in general terms: "Knowing how the brain works allows us to construct different teaching approaches." Several students have given general examples, without going into detail, as in this quote: "Neuroscience indicates a strong relationship between physical activity and cognition. This leads me to suggest a different approach, according to which students would be more physically active. In other words, learning would not entail only sitting in their seats' (approximately 10 NAP participants expressed this idea in various ways). Other students suggested approaches that they would use in the future or that they had already implemented in their classrooms:

From now on, when teaching a new learning assignment unit, I will divide the unit into several segments with structured breaks in between these segments, so as to heighten students interest, prevent fatigue, and stay within the optimal boundaries of time and information quantity that are most suited for storing information in short-term (working) memory. In the first teaching segment, I will present the new materials in the form of a slide presentation, a text to be read jointly, or as a lecture. For the second teaching segment, I will create an exercise that requires retrieving information learned in the first segment. In the third segment, I will assign students a task, which requires them to demonstrate their understanding by applying the knowledge. Between the segments, I will allow for small breaks of a few minutes, during which students will engage in active movement, through games, exercises, or a creative task. The goal of this kind of learning is to allow for repetition of information in separate segments of 10 to 15 minutes, to ensure that the new information presented will indeed be stored in their long-term memory. (Mentioned by three different students using various phrasing.)

An arithmetic and math teacher gave an example demonstrating the way she improved students' use of working memory as they solved arithmetic problems:

During one of the lessons in the course, at the class professor's request, I demonstrated an instruction method for teaching children to add and carry a number over to the next column. I showed them the way I teach the children in my class. Then when we analyzed my method, I understood the enormous mis- 
take I was making each time I taught the subject. The error that I made was telling the children to write down the number that was being carried over, without once thinking that I might tell them to "remember that number"... The simple act of remembering instead of writing is apparently important for strengthening students working memory. I have to say that this was quite alarming for me, and I knew that I had to change my teaching method and soon. In my next arithmetic class, we continued on the same topic, but this time I asked the children to remember the number. It was amazing to see how quickly the children adopted the new method. The practice segment went smoothly; the students did not feel that they were called upon to perform a complicated exercise. From then on, we continued to utilize working memory in the process of solving math exercises. In addition, when I taught them multiplication-using columns, we continued to use working memory when solving a problem. Nowadays, when I have a chance to work with other math teachers in my school, making suggestions and giving professional advice, I emphasize the importance of using working memory in the learning process.

The NAP participants emphasized that brain research findings have pointed to a strong link between physical activity and cognition. As one participant has written: this leads me to suggest a different approach, according to which my students would be more physically active in my classroom. In other words, learning would not entail merely sitting in their seats.

4) Acquiring understanding of how young people's brain functions directs teachers to change their approach to their students.

In addition to acquiring new tools and strategies, it became evident, upon reading project participants' reports, that they have changed the way they viewed students, both individually and in general, on the classroom level. For example, an NAP participant described an encounter with one of her students:

In my class, a student has difficulty getting organized for learning. He cannot find what he needs in his backpack, and there are always notebooks, workbooks and a lunchbox scattered around his seat. When writing in his notebooks, he switches sides, skips pages, writes outside the line and his handwriting is large and illegible; his notebooks are full of scribbles and erasures. Until now, I had acted intuitively, and classified this student as either "chronically erratic", "unpredictable", or "problematic". Now I understand his problem with organization and planning (functions of the prefrontal lobes and administrative functions). We prepared an illustrated chart with the weekly class schedule, emphasizing recess periods, and taped it to his desk. Together we made a drawing of the equipment he needs for each lesson and color-coded this: Language in red, arithmetic in blue, sciences in green, etc. At the end of each school day, together we checked that all of his pens and pencils were back in the box... Actually, relying on his visual memory, I created a pattern in his notebook for remembering the guidelines for proper class behavior.

The NAP participants referred not only to their relationships with specific 
students but also to factors relating to students in general, as the following quote exemplifies:

In the course, I learned that in a lesson that lasts more than two straight hours, students could deplete their attention cycle and become weary. Based on this information, I try to include activities to prevent such weariness, such as asking them to stand up and stretch, allowing them to eat a sandwich they brought, take a drink, and even to stand up and walk around for a minute. (Three additional students expressed this idea.)

Finally, the link between emotions and learning was remarkably underscored:

Findings from neuroscience can be very helpful for teachers in their daily work. [We learned about] the relationship between emotions and learning and the function of the amygdala. Students must be emotionally available in order to engage in learning: students who come back from recess after an incident involving shaming, violence, or even a disagreement with a friend cannot be expected to go back to learning as usual. The teacher should meet with them individually, conduct a constructive dialogue, and be prepared to listen. Together, the student and teacher should work on preparing resources for coping with stressful events or for addressing problems or threats that interfere with the student's ability to engage in the learning.

\section{Discussion and Conclusion}

We may conclude that the Neuropedagogy Adaptation Project (NAP) has shown that in-service teachers were capable of implementing neuroscience knowhow in their classroom functioning without breaking difficulty, have demonstrated a high level of comprehension, and attested to the significance of neuroscience to education. The NAP experience points to the assertion that joint efforts of scientists and teachers can make it possible to offer new pedagogical avenues and approaches that can potentially improve the quality of teaching and learning outcomes.

The NAP also suggests that it is important that teachers and educators be equipped with basic knowledge in the field of neuroscience and be familiar with the structure and function of the brain, its abilities and limitations. Exposure to neuroscience allows teachers to follow the ever-increasing developments emerging in the field of brain research and learning, to improve their teaching abilities, and thus the academic achievements of their students, while enhancing the pleasure that both they and their students derive from teaching and learning. This point is especially pertinent when preparing novice teachers for their future role.

Based on the conclusions derived from the project, we argue that the time is ripe for establishing a new educational discipline-Neuropedagogy, which is a blend of neuroscience, neurocognitive psychology and education. Implementing findings from neuroscience research in the pedagogical practice is particularly important currently, when the criticism and disillusionment with the education- 
al outcomes, both nationally and globally, mounts. Making neuroscience knowledge an inseparable component of teachers' pedagogical knowledge inventory can be one of the ways to ensure that neuropedagogy be used in the field of education, and serve its purposes. That is achievable by integrating neuroscience in the teacher-training curriculum, as well as in professional development seminars for in-service teachers. Neuropedagogy might potentially serve the makings for innovative teaching practices, enhance productive learning, and improve teacher-student relationships.

Our teaching approach in the three-year Neuropedagogy Adaptation Project (NAP) constitutes a change in the role assigned to experts from both in the fields of neurosciences and education. Typically, as noted by Daniel, the expectation is that experts in neuroscience research should be the initiators responsible for offering practical applications of their findings, whereas experts in education may play a passive role in implementing the offerings provided by neuroscience experts (Daniel, 2014). By contrast, neuroscience experts should ideally present their findings in an accessible and comprehensible manner to experts in the field of education. Then, it is the responsibility of educators and teachers to initiate, devise, and formulate appropriate ways for implementing neuroscience concepts and research findings to the field of education at large. Our teaching approach not only confirmed the findings of the long-term study conducted by Dubinsky, Roehrig and Varma (2013), as well as those of the study by Pickering and Howard-Jones (2007), but also offered practical suggestions for improving teaching and classroom management.

We cannot conclude this discussion without addressing an important-albeit not well-grounded claim, voiced mostly by researchers from the field of neuroscience, namely, that teachers trying to apply neuroscience to education may do so in an erroneous manner. This claim refers to teachers' inaccurate interpretations of neuroscientific information and its implications for the process of teaching and learning, or to teachers' thoughts and ideas, which may sound logical, but are not based on proven empirical facts-or on any fact, for that matter (Howard-Jones, 2014; Morein-Zamir \& Sahakian, 2010). Admittedly, neuroscience is a complex field, and understanding it-and especially applying neuroscientific findings to teaching - is no easy task. Our experience has indicated that in general, in no case did the project participants commit egregious errors or adopt improper perceptions (referred to as neuronal myths). This was due to the careful delivery of essential information throughout the project courses. However, there were cases, albeit not many, in which it appeared that project participants' interpretation of the material was too free, or misguided.

The NAP participants enrolled in the project voluntarily and, hence, we may assume that they were highly motivated to learn this particular subject. Indeed, they are the kind of participants that suit best for such experience. Had we found that these highly motivated educators were incapable of offering valid ways of applying their acquired knowledge of neuroscience to their teaching, we would 
have known that this endeavor might possibly be unsuitable for the general population of teachers.

\section{Conflicts of Interest}

The authors declare no conflicts of interest regarding the publication of this paper.

\section{References}

Ansari, D., Koning, J., Leask, M., \& Tokuhama-Espinosa, T. (2017). Developmental Cognitive Neuroscience: Implications for Teachers' Pedagogical Knowledge. In S. Guerriero (Ed.), Pedagogical Knowledge and the Changing Nature of the Teaching Profession (pp. 195-222). Paris: OECD Publishing. https://doi.org/10.1787/9789264270695-11-en

Ansari, D., Smedt, B., \& Grabner, R. H. (2011). Neuroeducation-A Critical Overview of an Emerging Field. Neuroethics, 5, 105-117. https://doi.org/10.1007/s12152-011-9119-3

Daniel, D. B. (2014). Preaching about Teaching: Translating Mind, Brain, and Education to the Classroom. Paper Presented at the Meeting of the International Mind, Brain, and Education Society, Fort Worth, TX.

Dubinsky, J. M., Roehrig, G., \&, Varma, S. (2013). Infusing Neuroscience into Teacher Professional Development. Educational Researcher, 42, 317-329. https://doi.org/10.3102/0013189X13499403

Fischer, K. W., \& Daniel, D. B. (2009). Need for Infrastructure to Connect Research with Practice in Education. Mind, Brain, and Education, 3, 1-2. https://doi.org/10.1111/j.1751-228X.2008.01054.x

Friedman, I., Teichman-Weinberg, A., \& Grobgeld, E. (2016). The Achva Model of Neuropedagogy: Applying Findings from Brain Research to Teaching and Learning. Achva Academic College.

Howard-Jones, P. A. (2014). Neuroscience and Education: Myths and Messages. Nature Reviews Neuroscience, 15, 817. https://doi.org/10.1038/nrn3817

Krippendorff, K. (2004). Content Analysis: An Introduction to Its Methodology. Thousand Oaks: Sage Publications.

Levit-Binnun, N., Hadar, L. L., Albelda, N., \& Ergaz, O. (2018). De-Educating "Neuromiths" through "Personal Brain Investigations": A Case Study of an Experimental Teacher Development Program. New York: The American Educational Research Association.

Morein-Zamir, S., \& Shakrian, B. S. (2010). Neuroethics and Public Engagement Training Needs for Neuroscientists. Trends in Cognitive Sciences, 14, 49-51. https://doi.org/10.1016/j.tics.2009.10.007

Pickering, S. J., \& Howard-Jones, P. (2007). Educators' Views on the Role of Neuroscience in Education: Findings from a Study of UK and International Perspectives. Mind, Brain, and Education, 1, 109-113. https://doi.org/10.1111/j.1751-228X.2007.00011.x

Tokuhama-Espinosa, T. (2018). Using Research from the Learning Sciences to Improve Teaching. New York: The American Educational Research Association.

Tokuhama-Espinosa, T. (2016). Making Classrooms Better. New York: W.W. Norton \& Company.

Tokuhama-Espinosa, T. (2011). Mind, Brain, and Education Science. A Comprehensive Guide to the New Brain-Based Teaching. New York: W.W. Norton \& Company. 